\title{
Devising a new approach to capitalism at home.
}

\author{
Kaori O’Connor (University College London)
}

In this paper I argue that if anthropology is to secure its future, it has to return to one of its historic projects, that of seeking to understand our own society. As Boas (1904: 522) put it, anthropology must study human culture in all the variety of its forms, past and present-including the society in which we ourselves live. In our society today, nothing is more central to everyday life than capitalism, its workings and its products. I describe my own doctoral research in which the concept of capitalism as a cultural system, as developed by Sahlins $(1976,1996,1998)$ and by Mintz (1986), is used to undertake a cultural analysis of the relationship between products, corporations and society. In doing so, I point to ways in which anthropology can provide unique insights into commerce. My work focuses on a single producer, product and cohort of consumers - the elite American corporation E. I. du Pont de Nemours (Dupont), the man-made fibre Lycra, and the so-called 'baby boomers', born in Britain and America between 1946 and 1964. By examining the history of this corporation, its invention and marketing of the fibre, and the significant role played by Lycra in the material life of this specific cohort, I was able to trace changes in social values through changes in products, gaining insights not easily obtained by direct observation or conscious explanation. By concentrating on the baby boomer cohort of consumers born between 1946 and 1964, I was able to explore changing attitudes to age in AngloAmerican society, where the aging of the population is an urgent concern.

There are two prime obstacles to the development of future fields at home which are rarely or insufficiently acknowledged. First, as Yanagisako (2002: xii) points out, there is our discipline's continuing 'predominant focus on working class, "subaltern" and "nonwestern" people', which has resulted, as Forman (1994: 7) says, in the marginalization of anthropology as a source of wisdom about the society in which we live. It also blinds us to the workings of the most influential sectors of our society. As Nader (1972, 1994, 1997) has long argued, we have to 'study up'. Second, there is the problem of the existence of competing fields such as human geography, sociology and cultural studies that seek to exclude further anthropology by asserting that they do in the mainstream of the developed world what we do in the margins, either in the developing world, or in the subaltern and alternative strata of our own society. To the extent that we persist in our disciplinary bias, or acquiesce in this casting of our role by others, the prospects are not encouraging. If we want to secure our future, we must remember that the original anthropological project, as Malinowski (1922: 517-8) said, was the study of other cultures 'with the ultimate aim of understanding our own'.

Following from this, two clear priorities emerge. Anthropology, as Rappaport (1995) observed, needs to engage with the central issues and processes of everyday life at home. In addition, we have to develop distinctive approaches that draw upon the established 
anthropological corpus to understand the workings of the complex, corporatized, capitalist society in which we live.

How can we do this? After nearly two decades of fragmentation, over-particularization, relativism and a distaste for history - during which time studies which aimed to widen the field effectively narrowed it by emphasizing diversity at the expense of mainstream culture - a new movement is emerging. There is a rekindled interest in elites following the continuing work of Nader (1972, 1994, 1997), while Moore (1994) and MacLennan (1995) advocate a processual analysis which combines ethnography and history. At the same time, the Comaroffs (1992) argue for a move away from a focus on the individual towards mainstream social and cultural forms which shape and constrain human action. There is also the rapprochement of anthropology and demography (see Kertzer and Fricke 1997), and Ortner's $(1999,2003)$ innovative use of cohort analysis to analyse social change and shifting values. All of these are responses to the need, highlighted by Yanagisako (2002), for anthropology to face up to capitalism in new ways. This methodological 'facing up' entails grappling with competing representations, having to deal with a well-recorded past, addressing the challenge of linking levels of analysis, engaging with large organizations and coming to terms with the sheer scale of the field while still using anthropological techniques. An example of such an approach might be found in Yanagisako (2002) when she uses kinship to throw light upon the internal culture of Italian family firms in the contemporary luxury textile trade. After years of micro-level, single-site subaltern studies, the big picture is back, a picture in which it is acceptable, and indeed necessary for heuristic purposes, to embrace statistics, to do anthropology in the archives, and even to generalize. On a further level, there is a retreat from over-theorizing and excessive reflexivity, and a renewed interest in direct and indirect observation rather than relying solely on what people say. Who-am-I, the great question of the critique of anthropology in the 1980s, and who-are-you, the query that unleashed the articulation of diversity and difference in the 1990s, are giving way to the reassertion of the discipline's original question, what's-going-on?

All of the foregoing informed my own recently completed $\mathrm{PhD}$ work, carried out in Britain and America, which involved devising and implementing an innovative approach to capitalism based upon three elements: the multi-site method, Sahlins's concept of capitalism as a cultural system $(1976,1996,1998)$, and material culture as taught at University College London (UCL) where it is a speciality.

To begin with the first, by 'multi-site method' I do not simply mean research carried out in several sites, or non-localized studies that concentrate on movement such as diasporas or trans-national commodity flows, but an aspect of the method that has so far received little attention. As Marcus $(1995,1998,1999)$, the main promulgator of multi-site research has observed, its full potential remains unexploited because multi-site investigations still tend to begin from over-determined and often linear starting points. In other words, we know what the connections are in advance, and our work merely adds flesh to the bones. Marcus argues that for the underlying objectives of the methodwhich are to avoid over-determination, to elicit and pursue unexpected juxtapositions and connections and to generate innovative problematizations - to be fully realized, investigations should begin from a starting point that poses questions without supplying answers, and leads simultaneously in many directions. 
A paradigmatic example of a starting point of this kind is what is known as the 'ethnographic moment'. These are epiphanies-moments of intuition or realization experienced during fieldwork or pre-fieldwork, that provide insight and a point of entry into the research that could not be arrived at simply though the exercise of logic. Such moments allow ethnographers to break through the barriers of naturalized values and common sense that are a particular problem for anthropologists working in their own society. Ethnographic moments are often indicative of dissonance (see Herzfeld 1997), as between competing accounts, contesting values or problematic social changes of some kind. Their meaning does not lie on the surface and they can simultaneously provide answers to which there are as yet no questions, and pose questions to which there are as yet no answers. When experienced, the anthropologist may intuit that something significant is going on, and for those responsive to the moment and the method, subsequent research will take the form of finding out just what this something is. The moment may arise from observed behaviour, as with Prost's (2003) experience in a temple in Dharamsala. In studies involving production and consumption in particular, the moment often involves a product or good which in some way reflects or objectifies larger forces or values. For Carrier (1993), insight into symbolic exchange in our society came through the contemplation of a wrapped Christmas present, while for Miller (1997), a handful of shiny peanuts encapsulated significant aspects of the ways in which global commodities were localized in Trinidad.

The ethnographic moment with which my work began involved both observed behaviour and a specific material object. In a large London department store, I observed a 40something woman shopper attempt to purchase Lycra leggings in size 16, the average size for that age group. She was looking for the long, footless exercise leggings associated with Jane Fonda and the aerobic fitness movement of the 1980s and still recommended for older exercisers by physiotherapists and fitness instructors because they give good muscular support, control wobble, let the instructor see that the limb is in proper alignment, don't flap around the ankle and make you trip, and don't make you slip if you are exercising barefoot. The store did not have what she was looking for, and I overheard the woman shopper complain that she had been to many places looking for large Lycra leggings, to no avail.

Now what was going on? I was not inclined to dismiss what I had observed as one woman's bad shopping day. For one thing, I knew that she was not alone. At 40something, my woman shopper and millions like her were members of the post World War II birth cohort known as the baby boomers, born in the developed world between 1946 and 1964, the largest cohort in history. In America, they comprise 27\% of the population compared to the cohort after them, the next largest, the so-called 'Generation $\mathrm{X}^{\prime}$ at $16.3 \%$. There are parallel figures for Britain, Canada and Australia. Apart from their size and the unprecedented levels of disposable income enjoyed by members of this cohort, something else distinguishes the baby boomers. Due to social and medical advances, boomers are healthier than preceding generations and are expected to live longer than any previous cohort. As they age, concern mounts over the projected social and medical costs of maintaining them in their later years. This in turn has led to the idea of the 'compression of morbidity' in which, as a matter of social policy, the middle aged are being actively encouraged to assume personal responsibility for their well-being, 


\section{Anthropology Matters Journal http://www.anthropologymatters.com}

notably through taking regular exercise, in order to avoid disabling chronic illnesses for as long as possible (Shield and Aronson 2002: 64). Women particularly benefit from aerobic exercise in the midlife and later, since it has been proven to ameliorate certain conditions linked to the hormonal changes after the menopause. So boomer women are there in their numbers, with disposable incomes and an interest in optimizing their health through exercise, or at least buying the clothes to do it in. Yet my woman shopper couldn't find Lycra leggings to buy. Did it matter? In my view, it did. The absence of suitable clothes is a disincentive to exercise that is ultimately bound to have wider individual and social consequences.

Retail ethnography, which I subsequently carried out in America and Britain, confirmed that the ethnographic moment was not an isolated event. Retail staff consistently reported that they were asked for Lycra exercise leggings 'all the time' by middle-aged women like my shopper. Mid-life women I observed and interviewed confirmed that they had had experiences identical to that of my first woman shopper. Yet at the same time I observed a surplus of exercise clothes for younger and smaller women, and saw manufacturers going out of business because they were overproducing for a youth market that was numerically smaller than the boomers. On the one hand, there was a demand with no supply, on the other, a supply with no demand. This is the kind of situation that the rationalist neoclassical model of supply and demand holds cannot exist, but it manifestly did.

Indeed, it is at this point in time in the social sciences generally that the inability of rationalist neoclassical economics to explain why we buy and don't buy - and why we produce and don't produce - is becoming apparent. Big business daily demonstrates that the so-called law of supply and demand does not always work, and not all commercial practices are rational. In Culture and Practical Reason, Sahlins used the American clothing system to portray capitalism as a cultural system, and to show 'how the so-called logic of capitalism is not sheer rationality but a form of a cultural order, or a cultural order acting in a particular form' (Sahlins 1976: 185). Beginning from the premise that goods materialize the social order, Sahlins sees in mass-produced goods a virtual map of the cultural universe, the meaningful differences substantiated in goods being the basic cultural distinctions, for example, classes, genders and age grades. Thus, goods objectify social categories and help to constitute them, and new social categories are objectified in new kinds of goods or modifications of old ones. Thus, Sahlins argues, instead of being a straightforward case of supply and demand, or of corporate manipulation, both production and consumption are culturally predicated, with the relationship between them a dialectical one sensitive to historical events and the effects of larger forces, in which neither the producer nor consumer is dominant.

Although a parallel approach was used by Mintz in his (1986) study of sugar, and more recently by Roseberry (1996) in his work on designer coffee as the objectifying product of the emergent yuppie class in America, it is outside anthropology where the potential in a cultural approach to capitalism is being more widely recognized. This can be seen in the geographers Jackson and Thrift's (1995) advocacy of historically and culturally specific studies that aim to transcend the traditional divisions between the 'economic' and the 'cultural', and studies like those of Lipartito and Sicilia (2004), arising from within economic history. They challenge standard assumptions about economic behaviour, 
moving away from the individualism and rationalism of neoclassical models to focus on 'what in traditional economics is left largely unexamined... society, culture and politics' (Lipartito and Sicilia 2004: 11). Other disciplines are discovering what Sahlins (1974) long ago called 'an economics properly anthropological', which cannot be comprehended in 'material terms' as distinct from 'social terms'.

Lycra leggings, or their lack, became the starting point of my study of capitalism as a cultural system, building on the work of Sahlins $(1976,1996,1998)$ and incorporating new interdisciplinary and anthropological developments. I employed the material culture method in which material objects become the vehicle for a wider analysis. Frequently used in traditional anthropology with hand-made or customized objects, the method is rarely employed at home with mass produced goods, and yet they are the natural link between production and consumption. By focusing on a particular object or product over time, we can advance our understanding of the links between the micro- and macrolevels. The need to be historically and culturally specific meant that I concentrated on a particular cohort of consumers, the baby boomers. I focused on women, but in order to understand the larger picture resisted becoming more specific, arguing that age 'cuts across' the specificities of ethnicity, class and locality. This resonated with new developments in anthropology and in demography (Ortner 1999, 2003; Kertzer and Fricke 1997). Lycra became the subject of a cultural biography in the manner developed by Kopytoff (1986), so that I followed Lycra and the boomer cohort, the generation for whom Lycra had been developed, from the present backwards in time. I began with the premise that the absence of Lycra leggings in the present (although a need for them demonstrably existed), compared with their ubiquity some 20 years previously, indicated a shift of cultural values and categories. These categories were expressed in material form such that they that were not necessarily recognized or acknowledged on the level of conscious explanation by either consumers or producers. Indeed, this is one of the strengths of the material culture method-by looking at objects, we may understand complex issues and embedded values that are difficult or impossible to observe or discuss directly. So what were these changes, and when had they begun?

This is where the unpredictability and full potential of the 'ethnographic moment' and 'multi-site method' came to the fore. At the outset I had not realized that Lycra had been invented and was still made only by a single producer, E. I. du Pont de Nemours and Company, the elite American transnational corporation who have long been the world leaders in the man-made fibre field. This fact moved the analysis into the vanguard area of the anthropology of corporate culture. To understand Lycra in the present, it was necessary to understand the history and culture of the corporation that had created it, and the external sociocultural and historic context in which the invention of Lycra took place. I had not envisioned this at the outset, but the method demands that unexpected connections be followed no matter where they lead, and indeed they proved rewarding. I negotiated access and cooperation with Dupont, who allowed me to carry out ethnography at Lycra trade fairs and promotional events. Most ethnography involving corporations tends to result in purely internal organizational studies, focusing on management or labour relations and conditions. By concentrating on the product and the relations between the corporation, its clients and consumers in the public arena, I was able to open new areas of analysis. I then discovered that Dupont had a remarkable 


\section{Anthropology Matters Journal http://www.anthropologymatters.com}

archive relating to the company's history and products going back two hundred years. While most ethnography of corporations is confined to the present, Dupont's archive allowed me to trace the way in which the company's distinctive corporate culture developed, and how this culture informed the development of the company and the creation of its products. Finally, it allowed me to examine the ways in which these products were presented to the consumer. The principles (or beliefs)-practices-products trajectory is fundamental in traditional anthropology; my work at Dupont revealed a parallel trajectory at the heart of contemporary corporate practice. In addition, Dupont's extensive marketing archive allowed me to address a long-standing lacuna: there is very little in the published literature about producers' intentions (O'Barr 1994), and consumer society has been studied from every angle except that of the producers (Blaszczyk 2000). The archival material enabled me to see consumers as producers see them, to understand how producers are constrained by culture and society, and to comprehend more about the ways in which the macro- and micro-levels are connected. Combining the archival material on Lycra with ethnography carried out among baby boomers, I was able to portray capitalism as a cultural system, showing how mass produced products come into being, acquire meaning, and how those meanings change for both producers and consumers over time. The lack of Lycra leggings with which the study began was revealed to be an example of one such change, tied to shifts in attitudes to age, to health and to fitness in the wider society. This provided important insights into attitudes to age which have proved notoriously difficult to study directly, despite the fact that the aging of the population is one of the most pressing issues of our time in the developed world. The potential in the anthropological study of capitalism as a cultural system is such that no single study fully can explore it, but I shall continue my work in the field and a full account of my Lycra research is in preparation (O'Connor 2006, see also O'Connor 2004).

The approach I took in my research, then, was not a conventional one, but it produced unexpected insights and opened up new areas of work in which vanguard anthropological approaches can be applied to the study of capitalism and mainstream society at home. Further, my work shows how the material culture method can give rise to new varieties of study - a notion which gains increasing recognition. As Marilyn Strathern (2003) said in a conference on material culture held at UCL, we have to learn not to resist being captured by the object. Additionally, my study established for man-made fibres what has long been recognized in more traditional studies within the anthropology of cloth-that textiles not only reflect social change but also create it, acting as an agent of history by giving cultural and material form to innovative dynamic moments. Above all, I hope that I have demonstrated that if we are to develop fully future fields at home, we need to resist over-determination, seek wide social relevance and go further in the direction of innovation and what Marcus calls 'opportunistic investigations' wherever they may lead. At the same time, we should continue to draw upon the rich area literature that gives us disciplinary identity and provides us with unique insights into our own society.

\section{References}

Blaszczyk, R.L. 2000. Imagining consumers: design and innovation from Wedgwood to Corning. Baltimore and London: Johns Hopkins University Press. 
Boas, F. 1904. The history of anthropology. Science 20: 513-24.

Carrier, J. 1993. The rituals of Christmas giving. In Unwrapping Christmas (ed) D. Miller. Oxford: Oxford University Press.

Comaroff J. \& J. Comaroff. 1992. Ethnography and the historical imagination. Boulder: Westview Press.

Forman, S. 1995. Introduction. In Diagnosing America: linking levels of analysis. (ed) S. Forman. Ann Arbor: University of Michigan Press.

Herzfeld, M. 1997. Anthropology and the politics of significance. Social Analysis. 41 (3): 107-38.

Jackson, P. \& N. Thrift. 1995. Geographies of consumption. In Acknowledging consumption: a review of new studies (ed) D. Miller. London and New York: Routledge.

Kertzer, D.I. \& T. Fricke. 1997. Towards an anthropological demography. In Anthropological demography: toward a new synthesis (eds) D.I. Kertzer \& T. Fricke. Chicago: University of Chicago Press.

Kopytoff, I. 1986. The cultural biography of things: commoditisation as process. In The social life of things (ed) A. Appadurai. Cambridge: Cambridge University Press.

Lipartito, K. \& D.B. Sicilia. 2004. Introduction: crossing corporate boundaries. In Constructing corporate America: history, politics, culture (eds) K. Lipartito \& D. Sicilia. Oxford and New York: Oxford University Press.

MacLennan, C. 1995. Democratic participation: a view from anthropology. In Diagnosing America: linking levels of analysis (ed) S. Foreman. Ann Arbor: University of Michigan Press.

Malinowski, B. 1922. Argonauts of the western Pacific. London: Routledge and Kegan Paul.

Marcus, G.E. 1995. Ethnography in/of the world system: the emergence of multi-sited ethnogaphy. Annual Review of Anthropology 24: 95-117.

Marcus, G.E. 1998. Ethnography through thick and thin. Princeton, New Jersey: Princeton University Press.

Marcus, G.E. 1999. Critical anthropology now: an introduction. In Critical anthropology now (ed) G.E. Marcus. Santa Fe, New Mexico: School of American Research Press.

Marcus, G.E. 2002. On the problematic contemporary reception of ethnography as the stimulus for innovations in its forms and norms in teaching and research. Anthropological Journal on European Culture 11: 191-206.

Miller, D. 1997. Capitalism: an ethnographic approach. Oxford: Berg.

Mintz, S. 1986. Sweetness and power: the place of sugar in modern history. New York: Viking.

Moore, S.F. 1994. The ethnography of the present and the analysis of process. In Assessing cultural anthropology (ed) R. Borofsky. New York and London: McGraw-Hill. 


\section{Anthropology Matters Journal http://www.anthropologymatters.com}

Nader, L. 1972. Up the anthropologist-perspectives gained from studying up. In Reinventing anthropology (ed) D. Hymes. New York: Pantheon Books.

Nader, L. 1994. Controlling processes. In Essays on controlling processes (ed) L. Nader. Kroeber Anthropological Society Papers. No 77. Berkeley: Department of Anthropology. University of California.

Nader, L. 1997. Controlling processes: tracing the dynamic components of power. Current Anthropology. 18 (5): 711-37.

O'Barr, W.M. 1994. Culture and the ad: exploring otherness in the world of advertising. Boulder and London: Westview Press.

O'Connor, K. 2004. The other half: the material culture of new fibers. In Clothing as material culture (eds) S. Kuechler \& D. Miller. Oxford and New York: Berg.

O'Connor, K. 2006. The biography of Lycra: material culture, business and society. (In preparation).

Ortner, S.B. 1999. Generation X: anthropology in a media-saturated world. In Critical Anthropology Now (ed) G.E. Marcus. Santa Fe, New Mexico: School of American Research Press.

Ortner, S.B. 2003. New Jersey dreaming: capital, culture and the class of 1958. Raleigh: Duke University Press.

Prost, A. 2003. Caught in an (ethnographic) moment: negotiating religious loyalties in and out of the field. Anthropology Matters Journal 2003-2.

Rappaport, R.A. 1995. Disorders of our own. In Diagnosing America: linking levels of analysis (ed) S. Forman. Ann Arbor: University of Michigan Press.

Roseberry, W. 1996. The rise of yuppie coffees and the reimagination of class in the United States. American Anthropologist 98 (4): 762-75.

Sahlins, M. 1974. Stone age economics. London: Tavistock Publications.

Sahlins, M. 1976. Culture and practical reason. Chicago: University of Chicago Press.

Sahlins, M. 1996. The sadness of sweetness: the native anthropology of western cosmology. Current Anthropology 37 (3): 395-427.

Sahlins, M. 1998. Cosmologies of capitalism: the trans-pacific sector of the world system. Radcliffe Brown Lecture in Social Anthropology. Proceedings of the British Academy LXXIV: 1-51.

Shield, R.R. \& S.M. Aronson. 2002. Aging in today's world: conversations between an anthropologist and a physician. New York and Oxford: Berghahn Books.

Strathern, M. 2003. Emblems, ornaments and inversions of value. Paper given at Translating things: clothing and innovation in the Pacific. A Wenner Gren/ESRC-funded conference hosted by University College London (UCL), June 23-25.

Yanagisako, S.J. 2002. Producing culture and capital: family firms in Italy. Princeton, New Jersey and Oxford: Princeton University Press. 


\begin{abstract}
About the Author
Dr Kaori O'Connor is an ESRC Postdoctoral Research Fellow in the Department of Anthropology, University College London. Her on-going research interests include the baby boomer cohort and its associated culture, man-made fibres, and the relationship between technology, business and society.
\end{abstract}

